\title{
A Systematic Review and Meta-analysis on the Epidemiology of the Muscular Dystrophies
}

\author{
Jean K. Mah, Lawrence Korngut, Kirsten M. Fiest, Jonathan Dykeman, \\ Lundy J. Day, Tamara Pringsheim, Nathalie Jette
}

\begin{abstract}
Background: The muscular dystrophies are a heterogeneous group of genetic muscle diseases with variable distribution of weakness and mode of inheritance. Methods: We previously performed a systematic review of worldwide population-based studies on Duchenne and Becker muscular dystrophies; the current study focused on the epidemiology of other muscular dystrophies using Medline and EMBASE databases. Two reviewers independently reviewed all abstracts, full-text articles, and abstracted data from 1985 to 2011. Pooling of prevalence estimates was performed using random-effect models. Results: A total of 1104 abstracts and 167 full-text articles were reviewed. Thirty-one studies met all eligibility criteria and were included in the final analysis. The overall pooled prevalence of combined muscular dystrophies was 16.14 (confidence interval [CI], 11.21-23.23) per 100,000. The prevalence estimates per 100,000 were 8.26 (CI, 4.99-13.68) for myotonic dystrophy, 3.95 (CI, 2.89-5.40) for facioscapulohumeral dystrophy, 1.63 (CI, 0.94-2.81) for limb girdle muscular dystrophy, and 0.99 (CI, 0.62-1.57) for congenital muscular dystrophies. Conclusions: The studies differed widely in their approaches to case ascertainment, and substantial gaps remain in the global estimates of many other types of muscular dystrophies. Additional epidemiological studies using standardized diagnostic criteria as well as multiple sources of case ascertainment will help address the economic impact and health care burden of muscular dystrophies worldwide.
\end{abstract}

RÉSUMÉ: Revue systématique et méta-analyse de l'épidémiologie des dystrophies musculaires. Contexte: Les dystrophies musculaires constituent un groupe hétérogène de maladies musculaires génétiques ayant une distribution de la faiblesse et une hérédité variables. Méthode: Nous avons effectué antérieurement une revue systématique des études populationnelles du monde entier sur la dystrophie musculaire de Duchenne et celle de Becker. Cette étude, effectuée dans les bases de données Medline et EMBASE, cible l'épidémiologie d'autres dystrophies musculaires. Deux examinateurs indépendants ont revu tous les résumés, le texte intégral des articles et les données publiées de 1985 à 2011. Le regroupement des estimés de prévalence a été effectué au moyen de modèles à effets aléatoires. Résultats: En tout, 1104 résumés et 167 articles en texte intégral ont été revus. Trente et une études rencontraient tous les critères d'éligibilité et ont été incluses dans l'analyse finale. La prévalence globale des dystrophies musculaires combinées était de 16,14 (intervalle de confiance [IC] de 11,21 à 23,23) par 100,000 de population. Les estimés de prévalence par 100,000 étaient de 8,26 (IC : 4,99 à 13,68) pour la dystrophie myotonique, 3,95 (IC : 2,89 à 5,40) pour la myopathie facio-scapulo-humérale, 1,63 (IC : 0,94 à 2,81) pour la myopathie scapulo-humérale et 0,99 (IC : 0,62 à 1,57) pour les dystrophies musculaires congénitales. Conclusions: Les études utilisaient des approches sensiblement différentes pour l'identification des cas et il existe des écarts considérables dans les estimés globaux de plusieurs autres types de dystrophies musculaires. D'autres études épidémiologiques utilisant des critères diagnostiques standardisés ainsi que de multiples sources d'identification des cas aideront à faire face à l'impact économique et au fardeau des soins de santé engendrés par les dystrophies musculaires à l'échelle mondiale.

Keywords: Epidemiology, muscular dystrophies, population-based, prevalence systematic review

doi:10.1017/cjn.2015.311

Can J Neurol Sci. 2016; 43: 163-177

The muscular dystrophies are a group of hereditary degenerative disorders associated with progressive muscle weakness. They can be transmitted as autosomal dominant, autosomal recessive, or X-linked traits; sporadic cases may also arise as a result of de novo mutation. Early presentation during childhood is generally associated with a more severe phenotype. Traditionally, the diagnosis is based on clinical and pathological features; more recently, the majority of muscular dystrophies have been classified based on molecular genetic confirmation. ${ }^{1}$ Research toward effective therapies is ongoing. Regional population-based prevalence estimates for the muscular dystrophies exist, but more precise pooled estimates representing the global burden of disease are unavailable. Robust pooled estimates are essential to facilitate the interpretation of clinical studies on molecular epidemiology, natural history, and impact of potential treatments.

From the Department of Clinical Neurosciences, University of Calgary, Calgary, Alberta, Canada (JKH, LK, KMF, JD, LJD, TP, NJ); Department of Pediatrics, Alberta Children's Hospital Research Institute, University of Calgary, Calgary, Alberta, Canada (JKM, TP); Hotchkiss Brain Institute, University of Calgary, Calgary, Alberta, Canada (JKM, LK, KMF, JK, NJ); Department of Community Health Sciences and O'Brien Institute for Public Health, University of Calgary, Calgary, Alberta, Canada (KMF, JK, NJ). Received February 13, 2015. Final Revisions Submitted May 10, 2015. Correspondence to: Jean K. Mah, Alberta Children's Hospital, 2888 Shaganappi Trail NW, Calgary, Alberta, Canada T3B 6A8. Email: jean.mah@albertahealthservices.ca 
In addition, analysis of economic impact and health care burden are contingent upon precise prevalence estimates. We previously reported on the epidemiology of Duchenne and Becker muscular dystrophies. ${ }^{2}$ The purpose of this study is to systematically evaluate the worldwide incidence and prevalence of other muscular dystrophies including myotonic dystrophy, facioscapulohumeral dystrophy, limb girdle muscular dystrophy, and congenital muscular dystrophy.

Myotonic dystrophy is an autosomal dominant disorder associated with clinical myotonia, progressive muscular weakness, and extramuscular manifestations such as cardiac arrhythmia and endocrine dysfunction. It is classified based on molecular genetic testing showing an expansion of trinucleotide (CTG) repeats on chromosome $19 \mathrm{q} 13.3$ for type 1 and tetranucleotide (CCTG) repeats on chromosome $3 \mathrm{q} 21.3$ for type 2 disease. ${ }^{3,4}$ Myotonic dystrophy type 1 can be subdivided into several clinical phenotypes depending on the age of presentation, including congenital, early childhood, adult, and late-onset forms. Congenital myotonic dystrophy type 1 is associated with multiple joint contractures, severe hypotonia, and generalized weakness; dysphagia and respiratory insufficiency leads to increased mortality during the neonatal period. ${ }^{5}$

Facioscapulohumeral dystrophy is an autosomal dominant disorder resulting from deletions within the D4Z4 repeat region located on chromosome 4q35 for type 1; mutations of SMCHD1 on chromosome $18 \mathrm{p} 11.32$ in association with a permission chromosome 4 allele account for the majority of type 2 disease. ${ }^{6,7}$ It results in progressive atrophy and, frequently, asymmetrical weakness in a descending pattern. Early-onset facioscapulohumeral dystrophy is associated with more severe weakness as well as central nervous system involvement such as mental retardation, epilepsy, retinal vasculopathy, and sensorineural hearing loss. ${ }^{8}$

Limb girdle muscular dystrophy refers to a heterogeneous group of autosomal muscular dystrophies with progressive weakness affecting predominantly the hip and shoulder girdles. It is further classified as either type 1 (dominant) or type 2 (recessive) disease based on the mode of inheritance, and labeled consecutively by letters of the alphabet according to the sequence of genes identified. It is related to mutations involving extracellular matrix or external membrane proteins, enzymes or proteins with putative enzymatic function, sarcolemma-associated proteins, nuclear membrane proteins, sarcomeric proteins, and other as-yet unspecified disorders. ${ }^{9}$

Congenital muscular dystrophy refers to a heterogeneous group of early-onset muscular dystrophies. Affected children are usually symptomatic at birth or before their first 6 months of life. The salient features include hypotonia, muscle weakness, and reduced deep tendon reflexes, with or without joint contractures. Feeding and respiratory insufficiency are common; additional features may include microcephaly, eye anomalies, cerebral malformation, joint laxity, muscle atrophy, or hypertrophy. It is further subdivided into disorders involving: (1) the basal lamina or extracellular matrix proteins; (2) alpha- dystroglycanopathy; (3) sarcoplasmic reticulum calcium release channel; (4) endoplasmic reticulum proteins; (5) nuclear envelope proteins; (5) mitochondrial membrane proteins; and (6) other unspecified dystrophies. $^{10}$

This study was part of a larger initiative funded by the Public Health Agency of Canada to facilitate better understanding of the burden of neurological illnesses in Canada and worldwide. ${ }^{11}$

\section{Methods}

\section{Search Strategy}

The search strategy was developed by the study authors with expertise in neurology and epidemiology and in consultation with a research librarian with systematic review expertise. The comprehensive systematic review was conducted on January 28, 2011, using Medline and EMBASE databases to identify worldwide population-based studies on the incidence and prevalence of muscular dystrophies. References were exported and managed using EndNote X5.

\section{Study Selection}

Two independent reviewers screened abstracts to determine eligibility for full-text review. Abstracts and titles of all references were screened independently, in duplicate, to identify original research articles reporting on the prevalence or incidence of muscular dystrophies, including congenital muscular dystrophy, myotonic dystrophy, facioscapulohumeral muscular dystrophy, limb girdle muscular dystrophy, Emery-Dreifuss muscular dystrophy, oculopharyngeal muscular dystrophy, severe childhood autosomal recessive muscular dystrophy, Duchenne muscular dystrophy, or Becker muscular dystrophy. Articles were included if they met the following criteria: (1) original research, (2) population-based, (3) reported an incidence or prevalence estimate of any muscular dystrophy, and (4) published in English or French. Studies were considered population-based if they used a sampling method meant to be representative of the entire population and/or were completed in a defined geographic area of known population size. Studies were excluded if they were clearly not populationbased, did not provide an estimate of incidence or prevalence, reported non-original data (i.e. reviews, letters, editorials), or if the study data were collected before 1985 . The decision to include publications from 1985 onward was based on the advent of molecular genetic testing as well as magnetic resonance imaging studies after 1985. The reference lists of excluded non-original data studies and the studies that were included in the review were manually searched for additional articles.

\section{Data Abstraction}

Two reviewers independently screened the full-text articles of abstracts identified in the first phase. Demographic data including age characteristics, race, sex, and geographic location were recorded. Diagnostic data were also collected, as were the sources of those data and the definitions/diagnostic criteria for muscular dystrophy. Incidence and prevalence estimates of muscular dystrophy from each study were recorded, along with any stratification by age or gender, if provided. Agreement at the abstract review stage was calculated using the Kappa statistic (see http:// www.cochrane.org/handbook/726-measuring-agreement). Disagreements between reviewers during abstract screening, full-text review, and/or data extraction were resolved by consensus and the use of a third reviewer as required.

\section{Study Quality}

Two reviewers independently completed a quality review for each study using a modified existing quality assessment tool. ${ }^{12}$ Quality scores were determined from eight key questions pertaining to sample representativeness, condition assessment, and 
statistical methods. Each study was given a quality score of 0 to 8 based on fulfillment of the quality criteria, as previously described. $^{2}$

\section{Statistical Analysis}

Estimates of point and period prevalence can vary widely depending on the natural history of a disease; in the current study, both forms of prevalence were considered together because of the irreversible nature of muscular dystrophy. The pooled prevalence of combined dystrophies including Duchenne, Becker, congenital, facioscapulohumeral, limb girdle, myotonic overall and myotonic, facioscapulohumeral, limb girdle, Emery-Dreifuss, and congenital muscular dystrophies by age group per 100,000 were calculated where appropriate. Estimates using total population (males and females) as the denominator were considered separately from those including only children in the denominator.

To be included in the meta-analysis, studies needed to report the number of cases and sample size, the estimate with accompanying confidence intervals, or the information required to calculate the missing values. To assess for significant between-study heterogeneity, the Cochrane Q statistic was calculated and $I^{2}$ was used to quantify the magnitude of between-study heterogeneity. An a priori decision was made to use a random effects model because of the heterogeneous nature of the condition. Publication bias was investigated visually using funnel plots and statistically using Begg's and Egger's tests. For all tests, a p value less than 0.05 was deemed to be statistically significant. All statistical analyses were carried out in $R$ (version 2.14$)^{13}$; the meta package (version 1.6-1.2010) was used to produce the stratified analyses and forest plots. ${ }^{14}$ The metafor package was used to produce the pooled estimates using restricted maximum likelihood estimation. $^{15}$

\section{RESULTS}

\section{Identification and Description of Studies}

The results of the combined search strategy yielded a total of 1104 citations; 167 articles met the criteria for full-text review. Thirty-one studies met all eligibility criteria and were included in the systematic review (Figure 1). Twenty-four studies were related to other muscular dystrophies apart from Duchenne and Becker muscular dystrophies.

\section{Systematic Review of Muscular Dystrophies}

Sixteen of the studies were conducted in Europe, including Darin and Tulinius, ${ }^{16}$ De Munain et al, ${ }^{17}$ Fanin et al, ${ }^{18,19}$

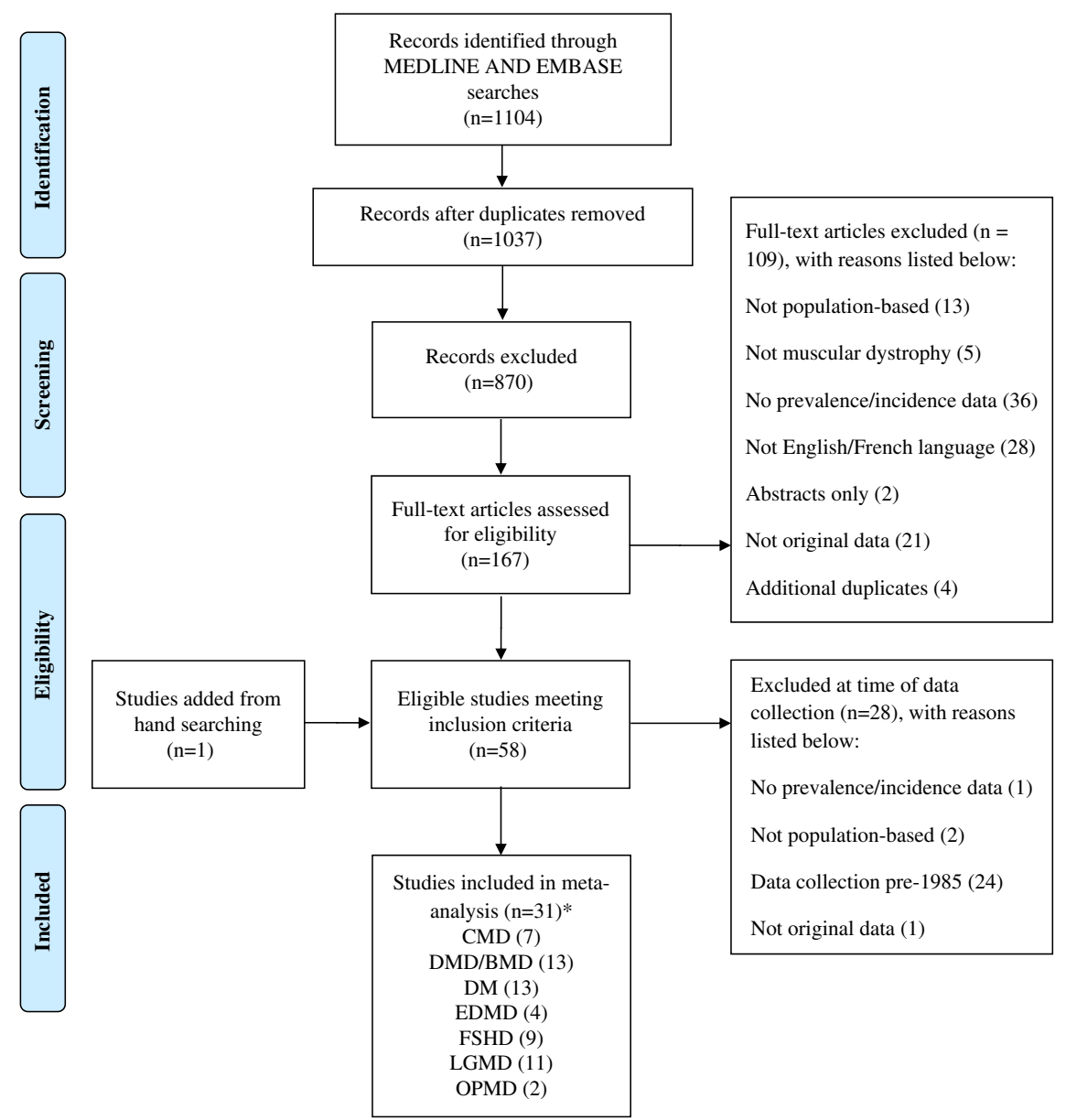

$\mathrm{DMD}=$ Duchenne muscular dystrophy, $\mathrm{BMD}=$ Becker muscular dystrophy, $\mathrm{DM}=$ myotonic dystrophy, $\mathrm{FSHD}=$ facioscapulohumeral muscular dystrophy, LGMD = limb girdle muscular dystrophy, EDMD = Emery-Dreifuss muscula dystrophy, CMD = congenital muscular dystrophy. *several publications reported data on multiple types of muscular dystrophies.

Figure 1: Flow chart of study selection. 
Table 1: Prevalence studies on myotonic dystrophy listed by study population and year of publication

\begin{tabular}{|c|c|c|c|c|c|c|c|c|}
\hline $\begin{array}{l}\text { First author, } \\
\text { publication year, } \\
\text { country, reference } \\
\text { number }\end{array}$ & Age (years) & $\begin{array}{l}\text { Reference for diagnostic } \\
\text { criteria }\end{array}$ & Data source & Diagnosis established by & $\begin{array}{l}\text { Prevalence } \\
\text { date }\end{array}$ & $\begin{array}{l}\text { Population } \\
\text { size (i.e. } \\
\text { denominator) }\end{array}$ & Number of cases & $\begin{array}{l}\text { Prevalence } \\
(95 \% \text { CI }) \\
\text { per 100,000 }\end{array}$ \\
\hline Chung, 2003, China ${ }^{35}$ & Children $<19$ & $\begin{array}{l}\text { Emery, 1991; World } \\
\text { Federation of Neurology } \\
\text { Research Group, } 1988\end{array}$ & Hospital/clinic chart review & $\begin{array}{l}\text { Medical chart review, muscle biopsy, } \\
\text { serum creatine kinase }\end{array}$ & 2001 & $1,335,469$ & 5 & 0.37 \\
\hline Darin, 2000, Sweden ${ }^{16}$ & Children $<16$ & Emery, 1997 & $\begin{array}{l}\text { Mailed survey, hospital/clinic } \\
\text { chart review, administrative } \\
\text { databases }\end{array}$ & $\begin{array}{l}\text { Clinical examination, serum creatine } \\
\text { kinase, } \pm \text { family history, } \pm \text { muscle } \\
\text { biopsy, } \pm \text { EMG }, \pm \text { genetic test }\end{array}$ & 1995 & 359,676 & 18 & $\begin{array}{l}5.00(2.97- \\
7.91)\end{array}$ \\
\hline $\begin{array}{l}\text { De Munain, 1993, } \\
\text { Spain }^{17}\end{array}$ & All & Harper, 1989 & $\begin{array}{l}\text { Mailed survey, hospital/clinic } \\
\text { chart review, family history }\end{array}$ & Medical chart review, \pm genetic test & 1991 & 689,836 & 183 & 26.53 \\
\hline $\begin{array}{l}\text { Ford, 2006, New } \\
\quad \text { Zealand }^{38}\end{array}$ & All, 16-74 & Unspecified & $\begin{array}{l}\text { Hospital/clinic chart review, } \\
\text { Patient registry, Family } \\
\text { History }\end{array}$ & $\begin{array}{l}\text { Clinical examination, medical chart } \\
\text { review, } \pm \text { genetic test for DM1 in } 10 / \\
21 \text { individuals }\end{array}$ & 2001 & 181,539 & 21 & 11.57 \\
\hline Hsiao, 2003, Taiwan ${ }^{36}$ & All, 1-80 & Unspecified & $\begin{array}{l}\text { Hospital/clinic chart review, } \\
\text { family history }\end{array}$ & $\begin{array}{l}\text { Medical chart review, } \pm \text { genetic test for } \\
\text { DM1 in } 59 / 96 \text { individuals }\end{array}$ & 2001 & $21,172,626$ & 96 & 0.45 \\
\hline Hughes, 1996, Ireland ${ }^{20}$ & All, $0.3-84$ & $\begin{array}{l}\text { Emery, 1994; World } \\
\text { Federation of Neurology } \\
\text { Research Group, } 1988\end{array}$ & $\begin{array}{l}\text { Mailed survey, hospital/clinic } \\
\text { chart review, administrative } \\
\text { databases, patient registry }\end{array}$ & $\begin{array}{l}\text { Clinical examination, medical chart } \\
\text { review }\end{array}$ & 1994 & $1,573,282$ & 134 & 8.52 \\
\hline Magee, 1999, Ireland ${ }^{21}$ & All & $\begin{array}{l}\text { Harper; 1973; Griggs and } \\
\text { Wood, 1989; Harley } \\
\text { et al } 1993\end{array}$ & $\begin{array}{l}\text { Mailed survey, hospital/clinic } \\
\text { chart review, administrative } \\
\text { databases, family history }\end{array}$ & $\begin{array}{l}\text { Medical chart review, } \pm \text { DM1 genetic } \\
\text { test in } 110 / 311 \text { at risk individuals }\end{array}$ & 1991 & $1,500,000$ & 185 & 12.33 \\
\hline Medica, 1997, Croatia $^{22}$ & All & Griggs and Woods, 1989 & $\begin{array}{l}\text { Hospital/clinic chart review, } \\
\text { patient registry, relatives }\end{array}$ & $\begin{array}{l}\text { Clinical examination, medical chart } \\
\text { review, } \pm \text { DM1 genetic test in } 27 / 33 \\
\text { cases }\end{array}$ & 1989 & 204,646 & 33 & 16.13 \\
\hline $\begin{array}{l}\text { Mladenovic, 2006, } \\
\text { Serbia }^{23}\end{array}$ & All, 1-60 & $\begin{array}{l}\text { Walton and Nattrass, 1954; } \\
\text { Gennarelli et al, } 1999\end{array}$ & $\begin{array}{l}\text { Hospital/clinic chart review, } \\
\text { patient registry }\end{array}$ & Medical chart review, Genetic test & 2002 & $1,602,226$ & 101 & $\begin{array}{l}6.30(5.13- \\
7.66)\end{array}$ \\
\hline $\begin{array}{l}\text { Nakagawa, 1991, } \\
\text { Japan }^{37}\end{array}$ & All & Griggs et al, 1989 & Hospital/clinic chart review & $\begin{array}{l}\text { Clinical examination, muscle biopsy, } \\
\text { serum creatine kinase }\end{array}$ & 1989 & $1,225,496$ & 112 & 9.14 \\
\hline $\begin{array}{l}\text { Norwood, 2009, } \\
\text { England }^{26}\end{array}$ & All & $\begin{array}{l}\text { Emery, 1998; Kaplan, } \\
2009\end{array}$ & $\begin{array}{l}\text { Hospital/clinic chart review, } \\
\text { administrative database, } \\
\text { relatives, patient registry }\end{array}$ & $\begin{array}{l}\text { Clinical exam, medical chart review, } \\
\text { genetic test, muscle biopsy }\end{array}$ & 2007 & $2,990,000$ & $\begin{array}{c}316 \\
\mathrm{DM} 1=311 \\
\mathrm{DM} 2=5\end{array}$ & $\begin{array}{l}10.57 \\
10.40 \\
0.17\end{array}$ \\
\hline $\begin{array}{l}\text { Segel, 2003, Israel } \\
\quad \text { (Jewish population) }\end{array}$ & All & Harper, 1989 & $\begin{array}{l}\text { Hospital/clinic chart review, } \\
\text { family history }\end{array}$ & $\begin{array}{l}\text { Clinical examination, medical chart } \\
\text { review, } \pm \text { DM1 genetic test in } 307 / 416 \\
\text { cases }\end{array}$ & 1994 & $4,441,000$ & 416 & 9.37 \\
\hline Siciliano, 2001, Italy ${ }^{27}$ & All, 6-86 & $\begin{array}{l}\text { Novelli et al, 1993; Walton } \\
\text { and Nattrass, } 1954\end{array}$ & $\begin{array}{l}\text { Mailed survey, hospital/clinic } \\
\text { chart review, patient registry, } \\
\text { relatives }\end{array}$ & $\begin{array}{l}\text { Medical chart review, } \pm \text { DM1 genetic } \\
\text { test in } 176 / 199 \text { cases }\end{array}$ & 1999 & $2,138,101$ & 199 & 9.31 \\
\hline
\end{tabular}

$\pm=$ with or without $\mathrm{CI}=$ confidence interval; DM1 = myotonic dystrophy type $1 ; \mathrm{DM} 2=$ myotonic dystrophy type 2 ; EMG = electromyography. 


\section{Table 2: Prevalence studies on facioscapulohumeral dystrophy listed by study population and year of publication}

\begin{tabular}{|c|c|c|c|c|c|c|c|c|}
\hline $\begin{array}{l}\text { First author, } \\
\text { year, country, } \\
\text { reference }\end{array}$ & Age (years) & $\begin{array}{l}\text { Reference for diagnostic } \\
\text { criteria }\end{array}$ & Data source & Diagnosis established by: & $\begin{array}{l}\text { Prevalence } \\
\text { date }\end{array}$ & $\begin{array}{l}\text { Population } \\
\text { size }\end{array}$ & $\begin{array}{l}\text { Number } \\
\text { of cases }\end{array}$ & $\begin{array}{l}\text { Prevalence } \\
(95 \% \text { CI ) per } \\
100,000\end{array}$ \\
\hline $\begin{array}{l}\text { Darin, 2000, } \\
\text { Sweden }{ }^{16}\end{array}$ & Children $<16$ & Emery, 1997 & $\begin{array}{l}\text { Mailed survey, hospital/clinic chart } \\
\text { review, administrative databases }\end{array}$ & $\begin{array}{l}\text { Clinical examination, serum creatine kinase, } \\
\pm \text { family history, } \pm \text { muscle biopsy, } \pm \text { EMG } \\
\pm \text { genetic test }\end{array}$ & 1995 & 359,676 & 3 & $\begin{array}{c}0.83 \\
(0.17-2.44)\end{array}$ \\
\hline $\begin{array}{l}\text { Chung, 2003, } \\
\text { China }^{35}\end{array}$ & Children $<19$ & $\begin{array}{l}\text { Emery, 1991; World } \\
\text { Federation of Neurology } \\
\text { Research Group, } 1988\end{array}$ & Hospital/clinic chart review & $\begin{array}{l}\text { Medical chart review, muscle biopsy, serum } \\
\text { creatine kinase }\end{array}$ & 2001 & $1,335,469$ & 1 & 0.07 \\
\hline $\begin{array}{l}\text { El-Tallawy, } \\
2005, \text { Egypt }^{33}\end{array}$ & All & Padberg, 1991 & Door-to-door survey & $\begin{array}{l}\text { Clinical examination, serum creatine kinase, } \\
\pm \text { muscle biopsy, } \pm \text { EMG }\end{array}$ & 1997 & 52,203 & 1 & 1.92 \\
\hline $\begin{array}{l}\text { Flanigan, 2001, } \\
\quad \text { United States } \\
39\end{array}$ & All & Not specified & $\begin{array}{l}\text { Hospital/clinic chart review, family } \\
\text { history }\end{array}$ & $\begin{array}{l}\text { Clinical examination, medical chart review, } \\
\text { genetic test }\end{array}$ & Undefined & $3,070,886$ & 208 & 6.77 \\
\hline $\begin{array}{l}\text { Hughes, 1996, } \\
\text { Ireland }^{20}\end{array}$ & All, $0.3-84$ & $\begin{array}{l}\text { Emery, 1994; World } \\
\text { Federation of Neurology } \\
\text { Research Group, } 1988\end{array}$ & $\begin{array}{l}\text { Mailed survey, hospital/clinic chart } \\
\text { review, administrative databases, } \\
\text { patient association }\end{array}$ & Clinical examination, medical chart review & 1994 & $1,573,282$ & 50 & 3.18 \\
\hline $\begin{array}{l}\text { Mostacciuolo, } \\
2009, \text { Italy }^{25}\end{array}$ & All, 26-87 & Emery, 1997 & Hospital/clinic chart review & $\begin{array}{l}\text { Clinical examination, medical chart review, } \\
\text { serum creatine kinase, genetic test, muscle } \\
\text { biopsy }\end{array}$ & 2004 & 871,190 & 40 & 4.59 \\
\hline $\begin{array}{l}\text { Nakagawa, 1991, } \\
\text { Japan }^{37}\end{array}$ & All & Walton and Nattrass, 1954 & Hospital/clinic chart review & $\begin{array}{l}\text { Clinical examination, Muscle biopsy, Serum } \\
\text { creatine kinase }\end{array}$ & 1989 & $1,225,496$ & 25 & 2.04 \\
\hline $\begin{array}{l}\text { Norwood, 2009, } \\
\text { England }^{26}\end{array}$ & All & Emery, 1998; Kaplan, 2009 & $\begin{array}{l}\text { Hospital/clinic chart review, } \\
\text { administrative database, relatives, } \\
\text { patient database }\end{array}$ & $\begin{array}{l}\text { Clinical examination, Medical chart review, } \\
\text { genetic test, muscle biopsy }\end{array}$ & 2007 & $2,990,000$ & 118 & $\begin{array}{c}3.95 \\
(3.27-4.73)\end{array}$ \\
\hline $\begin{array}{l}\text { Sposito, 2005, } \\
\text { Italy }^{28}\end{array}$ & All, 12-81 & Tawil et al, 1994 & $\begin{array}{l}\text { Hospital/clinic chart review, } \\
\text { administrative database, relatives }\end{array}$ & $\begin{array}{l}\text { Clinical examination, medical chart review, } \\
\text { genetic test }\end{array}$ & 2004 & $1,259,400$ & 58 & 4.61 \\
\hline
\end{tabular}

$\pm=$ with or without; $\mathrm{CI}=$ confidence interval; $\mathrm{EMG}=$ electromyography. 
Table 3: Prevalence studies on limb girdle muscular dystrophy listed by study population and year of publication

\begin{tabular}{|c|c|c|c|c|c|c|c|c|}
\hline $\begin{array}{l}\text { First author, year, } \\
\text { country, reference }\end{array}$ & Age (years) & $\begin{array}{l}\text { References for the } \\
\text { diagnostic criteria }\end{array}$ & Data source & Diagnosis established by: & $\begin{array}{l}\text { Prevalence } \\
\text { date }\end{array}$ & $\begin{array}{l}\text { Population } \\
\text { size }\end{array}$ & $\begin{array}{l}\text { Number } \\
\text { of cases }\end{array}$ & $\begin{array}{l}\text { Prevalence } \\
(95 \% \text { CI) per } \\
100,000\end{array}$ \\
\hline $\begin{array}{l}\text { Darin, 2000, } \\
\text { Sweden }{ }^{16}\end{array}$ & Children $<16$ & Emery, 1997 & $\begin{array}{l}\text { Mailed survey, hospital/clinic chart } \\
\text { review, administrative databases }\end{array}$ & $\begin{array}{l}\text { Clinical examination, serum creatine kinase } \\
\pm \text { family history, } \pm \text { muscle biopsy, } \pm \text { EMG }\end{array}$ & 1995 & 359,676 & 3 & $0.83(0.17-2.44)$ \\
\hline $\begin{array}{l}\text { Chung, 2003, } \\
\text { China }^{35}\end{array}$ & Children $<19$ & $\begin{array}{l}\text { Emery, 1991; World } \\
\text { Federation of } \\
\text { Neurology, } 1988 \\
\end{array}$ & Hospital/clinic chart review & $\begin{array}{l}\text { Medical chart review, muscle biopsy, serum } \\
\text { creatine kinase, EMG }\end{array}$ & 2001 & $1,335,469$ & 4 & 0.30 \\
\hline $\begin{array}{l}\text { El-Tallawy, } 2005, \\
\text { Egypt }^{33}\end{array}$ & All & Bushby, 1995 & Door-to-door survey & $\begin{array}{l}\text { Clinical examination, serum creatine kinase, } \\
\pm \text { muscle biopsy, } \pm \text { EMG }\end{array}$ & 1997 & 52,203 & 3 & 5.75 \\
\hline Fanin, 1997, Italy $^{18}$ & All, 2-44 & Unspecified & Hospital/clinic chart review & $\begin{array}{l}\text { Clinical examination, genetic test, medical } \\
\text { chart review, muscle biopsy, serum creatine } \\
\text { kinase }\end{array}$ & 1996 & $2,319,147$ & 18 & 0.56 \\
\hline Fanin, 2005, Italy ${ }^{19}$ & All & Unspecified & Hospital/clinic chart review & $\begin{array}{l}\text { Clinical examination, Serum creatine kinase, } \\
\text { Muscle biopsy, Genetic test }\end{array}$ & 2001 & $3,801,045$ & 36 & 0.95 \\
\hline $\begin{array}{l}\text { Hughes, } 1996, \\
\text { Ireland }^{20}\end{array}$ & All, 0-84 & $\begin{array}{l}\text { Emery, 1994; World } \\
\text { Federation of } \\
\text { Neurology, } 1988\end{array}$ & $\begin{array}{l}\text { Mailed survey, hospital/clinic chart } \\
\text { review, administrative databases, } \\
\text { patient registry }\end{array}$ & Clinical examination, medical chart review & 1994 & $1,573,282$ & 18 & 1.14 \\
\hline $\begin{array}{l}\text { Nakagawa, } 1991, \\
\text { Japan }^{37}\end{array}$ & All & $\begin{array}{l}\text { Walton and Nattrass, } \\
1954\end{array}$ & Hospital/clinic chart review & $\begin{array}{l}\text { Clinical examination, muscle biopsy, serum } \\
\text { creatine kinase }\end{array}$ & 1989 & $1,225,496$ & 19 & 1.55 \\
\hline $\begin{array}{l}\text { Norwood, 2009, } \\
\text { England }^{26}\end{array}$ & All & $\begin{array}{l}\text { Emery, 1998; Kaplan, } \\
2009\end{array}$ & $\begin{array}{l}\text { Hospital/clinic chart review, } \\
\text { administrative database, relatives, } \\
\text { patient database }\end{array}$ & $\begin{array}{l}\text { Clinical examination, medical chart review, } \\
\text { genetic test, muscle biopsy }\end{array}$ & 2007 & $2,990,000$ & 68 & $2.27(1.77-2.88)$ \\
\hline $\begin{array}{l}\text { Stensland, 2011, } \\
\quad \text { Norway }^{29}\end{array}$ & All & Undefined & Hospital/clinic chart review, relatives & $\begin{array}{l}\text { Medical chart review, questionnaire, genetic } \\
\text { test }\end{array}$ & 2008 & Undefined & 88 & 1.85 \\
\hline $\begin{array}{l}\text { Urtasun, } 1998, \\
\text { Spain }^{30}\end{array}$ & All, 16-71 & $\begin{array}{l}\text { Bushby and Beckman, } \\
1995\end{array}$ & Hospital/clinic chart review, registry & $\begin{array}{l}\text { Clinical examination, medical chart review, } \\
\text { genetic test, muscle biopsy, serum creatine } \\
\text { kinase }\end{array}$ & 1997 & 695,750 & 48 & 6.90 \\
\hline $\begin{array}{l}\text { van der Kooi, } \\
1996, \\
\text { Netherlands }^{31}\end{array}$ & All, 3-69 & Unspecified & Hospital/clinic chart review, relatives & $\begin{array}{l}\text { Clinical examination, medical chart review, } \\
\text { genetic test, muscle biopsy, serum creatine } \\
\text { kinase }\end{array}$ & 1993 & $15,239,182$ & 105 & 0.69 \\
\hline
\end{tabular}

$\pm=$ with or without $\mathrm{CI}=$ confidence interval $\mathrm{EMG}=$ electromyography. 
Table 4: Prevalence studies on Emery-Dreifuss muscular dystrophy listed by study population and year of publication

\begin{tabular}{|c|c|c|c|c|c|c|c|c|}
\hline $\begin{array}{l}\text { First author, } \\
\text { year, country, } \\
\text { reference }\end{array}$ & $\begin{array}{l}\text { Age } \\
\text { (years) }\end{array}$ & $\begin{array}{l}\text { References for } \\
\text { diagnostic } \\
\text { criteria }\end{array}$ & Data source & $\begin{array}{l}\text { Diagnosis established } \\
\text { by: }\end{array}$ & $\begin{array}{c}\text { Prevalence } \\
\text { date }\end{array}$ & $\begin{array}{c}\text { Population } \\
\text { size }\end{array}$ & $\begin{array}{l}\text { Number } \\
\text { of cases }\end{array}$ & $\begin{array}{c}\text { Prevalence } \\
(95 \% \mathrm{CI}) \\
\text { per } 100,000\end{array}$ \\
\hline $\begin{array}{l}\text { Chung, 2003, } \\
\text { China }^{35}\end{array}$ & $\begin{array}{c}\text { Children } \\
<19\end{array}$ & $\begin{array}{l}\text { Emery, 1991; } \\
\quad \text { World } \\
\text { Federation of } \\
\text { Neurology, } \\
1988\end{array}$ & Hospital/clinic chart review & $\begin{array}{l}\text { Medical chart review, } \\
\text { muscle biopsy, serum } \\
\text { creatine kinase }\end{array}$ & 2001 & $1,335,469$ & 3 & 0.22 \\
\hline $\begin{array}{l}\text { El-Tallawy, } \\
2005, \\
\text { Egypt }^{33}\end{array}$ & All ages & Undefined & Door-to-door survey & $\begin{array}{l}\text { Clinical examination, } \\
\text { serum creatine kinase, } \\
\pm \text { muscle biopsy, } \\
\pm \text { EMG }\end{array}$ & 1997 & 52,203 & 1 & 1.92 \\
\hline $\begin{array}{l}\text { Hughes, 1996, } \\
\text { Ireland }^{20}\end{array}$ & $\begin{array}{r}\text { All ages, } \\
0.3-84\end{array}$ & $\begin{array}{l}\text { Emery; 1994; } \\
\quad \text { World } \\
\text { Federation of } \\
\text { Neurology, } \\
1988\end{array}$ & $\begin{array}{l}\text { Mailed survey, hospital/clinic } \\
\text { chart review, administrative } \\
\text { databases, patient registry }\end{array}$ & $\begin{array}{l}\text { Clinical examination, } \\
\text { medical chart review }\end{array}$ & 1994 & $1,573,282$ & 7 & 0.44 \\
\hline $\begin{array}{l}\text { Norwood, } \\
2009, \\
\text { England }^{26}\end{array}$ & All & $\begin{array}{l}\text { Emery, 1998; } \\
\quad \text { Kaplan, } 2009\end{array}$ & $\begin{array}{c}\text { Hospital/clinic chart review, } \\
\text { administrative database, } \\
\text { relatives, patient database }\end{array}$ & $\begin{array}{l}\text { Clinical examination, } \\
\text { medical chart review, } \\
\text { genetic test, muscle } \\
\text { biopsy }\end{array}$ & 2007 & $2,990,000$ & 4 & $\begin{array}{c}0.13 \\
(0.04-0.34)\end{array}$ \\
\hline
\end{tabular}

$\pm=$ with or without; $\mathrm{CI}=$ confidence interval; $\mathrm{EMG}=$ electromyography.

Table 5: Prevalence studies on congenital muscular dystrophy listed by study population and year of publication

\begin{tabular}{|c|c|c|c|c|c|c|c|c|}
\hline $\begin{array}{l}\text { First author, } \\
\text { year, country, } \\
\text { reference }\end{array}$ & $\begin{array}{l}\text { Age } \\
\text { (years) }\end{array}$ & $\begin{array}{l}\text { References for } \\
\text { the diagnostic } \\
\text { criteria }\end{array}$ & Data source & Diagnosis established by: & $\begin{array}{c}\text { Prevalence } \\
\text { date }\end{array}$ & $\begin{array}{l}\text { Population } \\
\text { Size }\end{array}$ & $\begin{array}{l}\text { Number } \\
\text { of cases }\end{array}$ & $\begin{array}{c}\text { Prevalence } \\
(95 \% \mathrm{CI}) \\
\text { per } 100,000\end{array}$ \\
\hline \multicolumn{9}{|l|}{ All ages } \\
\hline $\begin{array}{l}\text { Hughes, } 1996, \\
\text { Ireland }^{20}\end{array}$ & $\begin{array}{r}\text { All ages, } \\
0.3-84\end{array}$ & $\begin{array}{l}\text { Emery, 1994; } \\
\text { World } \\
\text { Federation of } \\
\text { Neurology, } \\
1988\end{array}$ & $\begin{array}{l}\text { Mailed survey, hospital/ } \\
\text { clinic chart review, } \\
\text { administrative data, } \\
\text { registry }\end{array}$ & $\begin{array}{l}\text { Clinical examination, chart } \\
\text { review }\end{array}$ & 1994 & $1,573,282$ & 9 & 0.57 \\
\hline $\begin{array}{l}\text { El-Tallawy, } \\
2005, \\
\text { Egypt }^{33}\end{array}$ & All ages & Not specified & $\begin{array}{l}\text { Door-to-door community } \\
\text { survey }\end{array}$ & $\begin{array}{l}\text { Clinical examination, serum } \\
\text { creatine kinase, } \pm \text { muscle } \\
\text { biopsy, } \pm \text { EMG }\end{array}$ & 1997 & 52,203 & 2 & 3.83 \\
\hline $\begin{array}{l}\text { Nakagawa, } \\
\text { 1991, } \\
\text { Japan }^{37}\end{array}$ & All ages & Fukuyama, 1960 & $\begin{array}{l}\text { Hospital/clinic chart } \\
\text { review }\end{array}$ & $\begin{array}{l}\text { Clinical examination, serum } \\
\text { creatine kinase, muscle } \\
\text { biopsy }\end{array}$ & 1989 & $1,225,496$ & 14 & 1.14 \\
\hline $\begin{array}{l}\text { Norwood, } \\
2009, \\
\text { England }^{26}\end{array}$ & All ages & $\begin{array}{l}\text { Emery, 1998; } \\
\text { Kaplan, } 2009\end{array}$ & $\begin{array}{l}\text { Hospital/clinic chart } \\
\text { review, administrative } \\
\text { database, relatives, } \\
\text { registry }\end{array}$ & $\begin{array}{l}\text { Clinical examination, serum } \\
\text { creatine kinase, muscle } \\
\text { biopsy, genetic testing }\end{array}$ & 2007 & $2,999,000$ & 27 & 0.90 \\
\hline \multicolumn{9}{|l|}{ Children only } \\
\hline $\begin{array}{l}\text { Chung, 2003, } \\
\text { China }^{35}\end{array}$ & $\begin{array}{l}\text { Children } \\
<19 \\
\text { yrs }\end{array}$ & $\begin{array}{l}\text { Emery, 1991; } \\
\text { World } \\
\text { Federation of } \\
\text { Neurology, } \\
1988\end{array}$ & $\begin{array}{l}\text { Hospital/clinic chart } \\
\text { review }\end{array}$ & $\begin{array}{l}\text { Clinical examination, serum } \\
\text { creatine kinase, muscle } \\
\text { biopsy, EMG }\end{array}$ & 2001 & $1,335,469$ & 4 & 0.30 \\
\hline $\begin{array}{l}\text { Darin, } 2000 \\
\text { Sweden }^{16}\end{array}$ & $\begin{array}{l}\text { Children } \\
\quad<16\end{array}$ & Emery, 1997 & $\begin{array}{l}\text { Mailed survey, hospital/ } \\
\text { clinic chart review, } \\
\text { Administrative } \\
\text { databases }\end{array}$ & $\begin{array}{l}\text { Clinical examination, serum } \\
\text { creatine kinase, } \pm \text { family } \\
\text { history, } \pm \text { muscle biopsy, } \\
\pm \text { EMG }\end{array}$ & 1995 & 359,676 & 9 & $\begin{array}{c}2.50 \\
(1.14-4.75)\end{array}$ \\
\hline $\begin{array}{l}\text { Mostacciuolo, } \\
\text { 1996, } \\
\text { Italy }^{24}\end{array}$ & $\begin{array}{l}\text { Children } \\
\quad<21\end{array}$ & $\begin{array}{l}\text { International } \\
\text { Consortium on } \\
\text { CMD }\end{array}$ & $\begin{array}{l}\text { Hospital/clinic chart } \\
\text { review, Relatives, } \\
\text { Registry }\end{array}$ & $\begin{array}{l}\text { Clinical examination, serum } \\
\text { creatine kinase, muscle } \\
\text { biopsy }\end{array}$ & 1993 & $2,586,830$ & 17 & 0.66 \\
\hline
\end{tabular}

$\pm=$ with or without $\mathrm{CI}=$ confidence interval; $\mathrm{EMG}=$ electromyography. 


\section{Table 6: Prevalence studies on oculopharyngeal muscular dystrophy listed by study population and year of publication}

\begin{tabular}{|c|c|c|c|c|c|c|c|c|}
\hline $\begin{array}{l}\text { First author, } \\
\text { year, country, } \\
\text { reference }\end{array}$ & Age & $\begin{array}{l}\text { References for } \\
\text { the diagnostic } \\
\text { criteria }\end{array}$ & Data source & Diagnosis established by: & $\begin{array}{c}\text { Prevalence } \\
\text { date }\end{array}$ & $\begin{array}{c}\text { Population } \\
\text { size }\end{array}$ & $\begin{array}{l}\text { Number } \\
\text { of cases }\end{array}$ & $\begin{array}{c}\text { Prevalence } \\
(95 \% \text { CI }) \text { per } \\
100,000\end{array}$ \\
\hline $\begin{array}{l}\text { Blumen, 1997, } \\
\text { Israel }^{32}\end{array}$ & All & Not specified & $\begin{array}{l}\text { Hospital/clinic chart review, } \\
\text { neighborhood and community } \\
\text { surveys }\end{array}$ & $\begin{array}{l}\text { Clinical examination, medical } \\
\text { chart review }\end{array}$ & Undefined & 70,000 & 117 & 167.14 \\
\hline $\begin{array}{l}\text { Norwood, 2009, } \\
\text { England }^{26}\end{array}$ & All & $\begin{array}{l}\text { Emery, 1998; } \\
\quad \text { Kaplan, 2009 }\end{array}$ & $\begin{array}{l}\text { Hospital/clinic chart review, } \\
\text { administrative database, } \\
\text { relatives, patient database }\end{array}$ & $\begin{array}{l}\text { Clinical examination, medical } \\
\text { chart review, genetic test, } \\
\text { muscle biopsy }\end{array}$ & 2007 & $2,990,000$ & 4 & $\begin{array}{c}0.13 \\
(0.04-0.34)\end{array}$ \\
\hline
\end{tabular}

$\mathrm{CI}=$ confidence interval.

Hughes et al, ${ }^{20}$ Magee and Nevin, ${ }^{21}$ Medica et al, ${ }^{22}$ Mladenovic et al, ${ }^{23}$ Mostacciuolo et al, ${ }^{24,25}$ Norwood et al, ${ }^{26}$ Siciliano et al, ${ }^{28}$ Sposito et al; Stensland et al, ${ }^{29}$ Urtasun et al, ${ }^{30}$ and van der Kooi et al. $^{31}$ Three studies were from the Middle East, including Blumen et al, ${ }^{32}$ El-Tallawy et al, ${ }^{33}$ and Segel et al ${ }^{34}$; three studies were from Asia, including Chung et al, ${ }^{35}$ Hsiao et $a l^{36}$ and Nakagawa et $\mathrm{al}^{37}$; one study by Ford et al was from New Zealand $^{38}$; and one study by Flanigan et al was from North America. ${ }^{39}$ All 24 studies reported on the prevalence of muscular dystrophy; no studies reported on its incidence. The studies were hospital- or clinic-based estimates of the prevalence of muscular dystrophies, with the exception of one door-to-door home-based survey by El-Tallawy et al in 2005. ${ }^{33}$

The diagnostic criteria for muscular dystrophies were based on predefined criteria including the age of onset and distribution of muscle weakness, associated symptoms, rate of disease progression, family history, serum creatine kinase, and histological studies, with or without neurophysiology tests such as electromyography and nerve conduction studies (Tables 1-6). Genetic data were not specified in earlier studies by Hughes et al, ${ }^{20}$ Darin and Tulinius, ${ }^{16}$ Chung et al, ${ }^{35}$ El-Tallawy et al, ${ }^{33}$ Mostacciuolo et al, ${ }^{24}$ Nakagawa et al, ${ }^{37}$ van der Kooi et al, ${ }^{31}$ and Blumen et al. ${ }^{32}$ Molecular genetic testing was used for diagnosis in some but not all patients in other studies by De Munain et al, ${ }^{17}$ Ford et al, ${ }^{38}$ Hsiao et al, ${ }^{36}$ Magee \& Nevin, ${ }^{21}$ Medica et al, ${ }^{22}$ Segel et al, ${ }^{34}$ Siciliano et al, ${ }^{27}$ and Urtasun et al. ${ }^{30}$ Genetic confirmation in most or all patients was reported by Norwood et al, ${ }^{26}$ Mladenovic et $\mathrm{al}^{23}{ }^{28}$ Fanin et al, ${ }^{18}$ Fanin et al, ${ }^{19}$ Stensland et al, ${ }^{29}$ Sposito et al, ${ }^{28}$ and Mostacciuolo et al. ${ }^{25}$

\section{Myotonic Dystrophy}

Thirteen studies reported on the prevalence of myotonic dystrophy, and all were included in the meta-analysis. The majority of the studies did not distinguish between types 1 and 2 diseases. Eleven studies focused on all age groups, including De Munain et al, ${ }^{17}$ Ford et al, ${ }^{38}$ Hsiao et $a l,{ }^{36}$ Hughes et $a l,{ }^{20}$ Magee and Nevin, ${ }^{21}$ Medica et al, ${ }^{22}$ Mladenovic et al, ${ }^{23}$ Nakagawa et al, ${ }^{37}$ Norwood et al, ${ }^{26}$ Segel et al, ${ }^{34}$ and Siciliano et al. ${ }^{27}$ Studies by Darin and Tulinius ${ }^{16}$ and Chung et $\mathrm{al}^{35}$ involved children only (Figure 2). The pooled prevalence of myotonic dystrophy in all age groups was 8.26 per $100,000(95 \%$ confidence interval [CI], 4.99-13.68), and 1.41 per 100,000 (95\% CI, 0.11-17.85) in children alone. Significant heterogeneity existed among studies of all age groups $\left(I^{2}=99.1 \%, \mathrm{p}<0.0001\right)$ and between the two pediatric studies $\left(I^{2}=96.2 \%, \mathrm{p}<0.0001\right)$.

\section{Facioscapulohumeral Dystrophy}

Nine studies reported on the prevalence of facioscapulohumeral dystrophy and all were included in the meta-analysis. Seven studies reported on all age groups, including El-Tallawy et $\mathrm{al}^{33}$ Flanigan et al, ${ }^{39}$ Hughes et al, ${ }^{20}$ Mostacciuolo et al, ${ }^{25}$ Nakagawa et $\mathrm{al}^{37}$ Norwood et $\mathrm{al}^{26}$ and Sposito et al. ${ }^{28}$ Two studies by Darin and Tulinius ${ }^{16}$ and Chung et $\mathrm{al}^{35}$ focused on children only (Figure 3). The pooled prevalence of facioscapulohumeral dystrophy in all age groups was 3.95 per $100,000(95 \%$ CI, 2.89-5.40). The pooled prevalence in children only was 0.29 per 100,000 (95\% CI, 0.03-3.00). Significant heterogeneity was present for both groups $\left(I^{2}=89.5 \%, \mathrm{p}<0.0001\right.$ for all ages, and $I^{2}=77.1 \%, \mathrm{p}=0.04$ for children only).

\section{Limb Girdle Muscular Dystrophy}

Eleven studies reported on the prevalence of limb girdle muscular dystrophy and were included in the meta-analysis: nine reported on all age groups, including El-Tallawy et al, ${ }^{33}$ Fanin et $a{ }^{18,19}$ Hughes et al, ${ }^{20}$ Nakagawa et al, ${ }^{37}$ Norwood et al, ${ }^{26}$ Stensland et al, ${ }^{29}$ Urtasun et al, ${ }^{30}$ and van der Kooi et al. ${ }^{31}$ Two studies by Darin and Tulinius ${ }^{16}$ and Chung et $\mathrm{al}^{35}$ focused on children alone (Figure 4). Among studies including all age groups, the pooled prevalence of limb girdle muscular dystrophy was 1.63 per 100,000 (95\% CI, 0.94-2.81). In children alone, the pooled prevalence was 0.48 per 100,000 (95\% CI, 0.18-1.31). Significant heterogeneity was present for studies reporting on all age groups $\left(I^{2}=96.3 \%, \mathrm{p}<0.0001\right)$, but not for those including children only $\left(I^{2}=44.4 \%, \mathrm{p}=0.18\right)$.

\section{Emery-Dreifuss Muscular Dystrophy}

Four studies reported on the prevalence of Emery-Dreifuss muscular dystrophy. Three studies reported on all age groups and were included in the meta-analysis, including El-Tallawy et al, ${ }^{33}$ Hughes et al, ${ }^{20}$ and Norwood et al. ${ }^{26}$ Chung et al ${ }^{35}$ was the only pediatric study, with a prevalence of 0.22 per 100,000 children. The pooled prevalence of Emery-Dreifuss muscular dystrophy in all age groups was 0.39 per 100,000 (95\% CI, 0.12-1.30; Figure 5), with significant heterogeneity among the estimates $\left(I^{2}=71.3 \%, \mathrm{p}=0.03\right)$.

\section{Congenital Muscular Dystrophy}

Four studies reported on the prevalence of congenital muscular dystrophy in all age groups, including El-Tallawy et al, ${ }^{33}$ Hughes et al, $^{20}$ Nakagawa et al, ${ }^{37}$ and Norwood et al. ${ }^{26}$ Three studies 


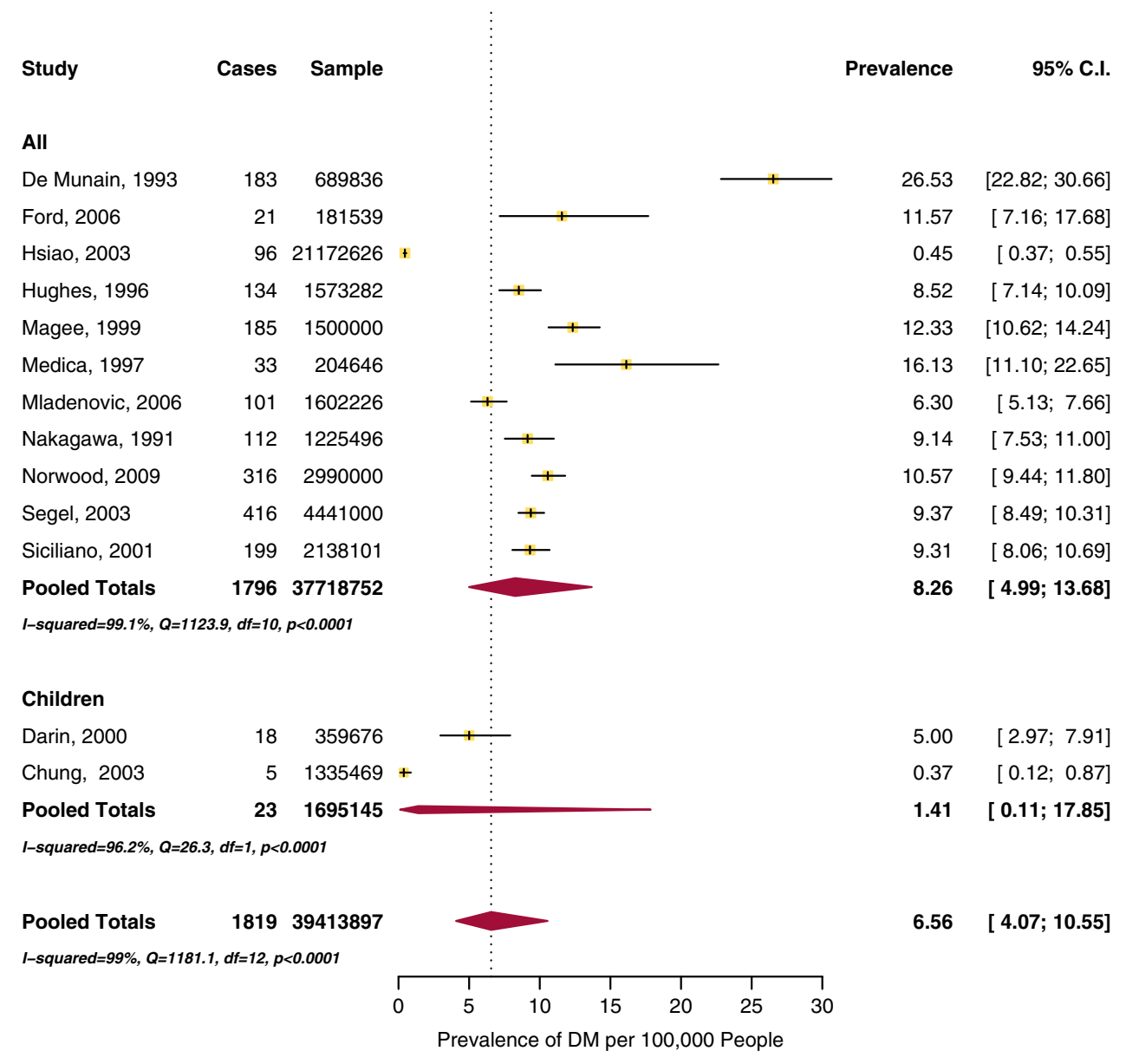

Figure 2: Forest plots of individual studies and pooled prevalence estimates of myotonic dystrophy (DM).

reported on the prevalence in children alone, including Darin and Tulinius, ${ }^{16}$ Chung et al, ${ }^{35}$ and Mostacciuolo et $\mathrm{al}^{24}$ (Figure 6). The pooled prevalence of congenital muscular dystrophy in all age groups was 0.99 per 100,000 (95\% CI, 0.62-1.57), and 0.82 per 100,000 (95\% CI, 0.27-2.47) in children only. Significant heterogeneity was present among the pediatric studies $\left(I^{2}=87.4 \%\right.$, $\mathrm{p}=0.0003$ ) but not for studies reporting on all age groups $\left(I^{2}=55.5 \%, \mathrm{p}=0.08\right)$.

\section{Oculopharyngeal Muscular Dystrophy}

Two studies described the prevalence of oculopharyngeal muscular dystrophy in all age groups, including Blumen et $\mathrm{al}^{32}$ and Norwood et al. ${ }^{26} \mathrm{~A}$ pooled analysis was not performed because of the limited number of studies.

\section{Combined Muscular Dystrophies}

Five studies reported on the overall prevalence of combined muscular dystrophies, including Duchenne muscular dystrophy, Becker muscular dystrophy, congenital muscular dystrophy, facioscapulohumeral dystrophy, limb girdle muscular dystrophy, and myotonic dystrophy by Chung et al, ${ }^{35}$ Darin and Tulinius, ${ }^{16}$ Hughes et al, ${ }^{20}$ Nakagawa et $a l,{ }^{37}$ and Norwood et al. ${ }^{26}$ The overall pooled prevalence of combined muscular dystrophies was
16.14 per 100,000 (95\% CI, 11.21-23.23). Random effects model showed significant heterogeneity, with $I^{2}=97.5 \%, \mathrm{p}<0.0001$ (Figure 7).

\section{Publication Bias}

Using both Begg's and Egger's tests, no evidence of publication bias was found for the muscular dystrophies ( $p>0.05)$, apart from facioscapulohumeral dystrophy. There was evidence of publication bias based on Egger's test for facioscapulohumeral dystrophy $(\mathrm{p}=0.008)$, but not Begg's $(\mathrm{p}=0.13)$; visual inspection of the funnel plot revealed an asymmetry, suggesting the potential of missing studies with a lower prevalence.

\section{Study Quality}

As indicated in Table 7, there were notable differences in research methodology as well as study quality. The median study quality score for studies reporting on the prevalence of muscular dystrophies was 7 of 8 (range, 4-8). All 31 articles described the target population in detail and 27 of 31 studies sampled either the entire population or used probability sampling. Of those studies necessitating a response rate, 26 reported a response rate greater than $70 \%$ and described the nonresponders adequately. The majority of studies reported on whether their sample was 


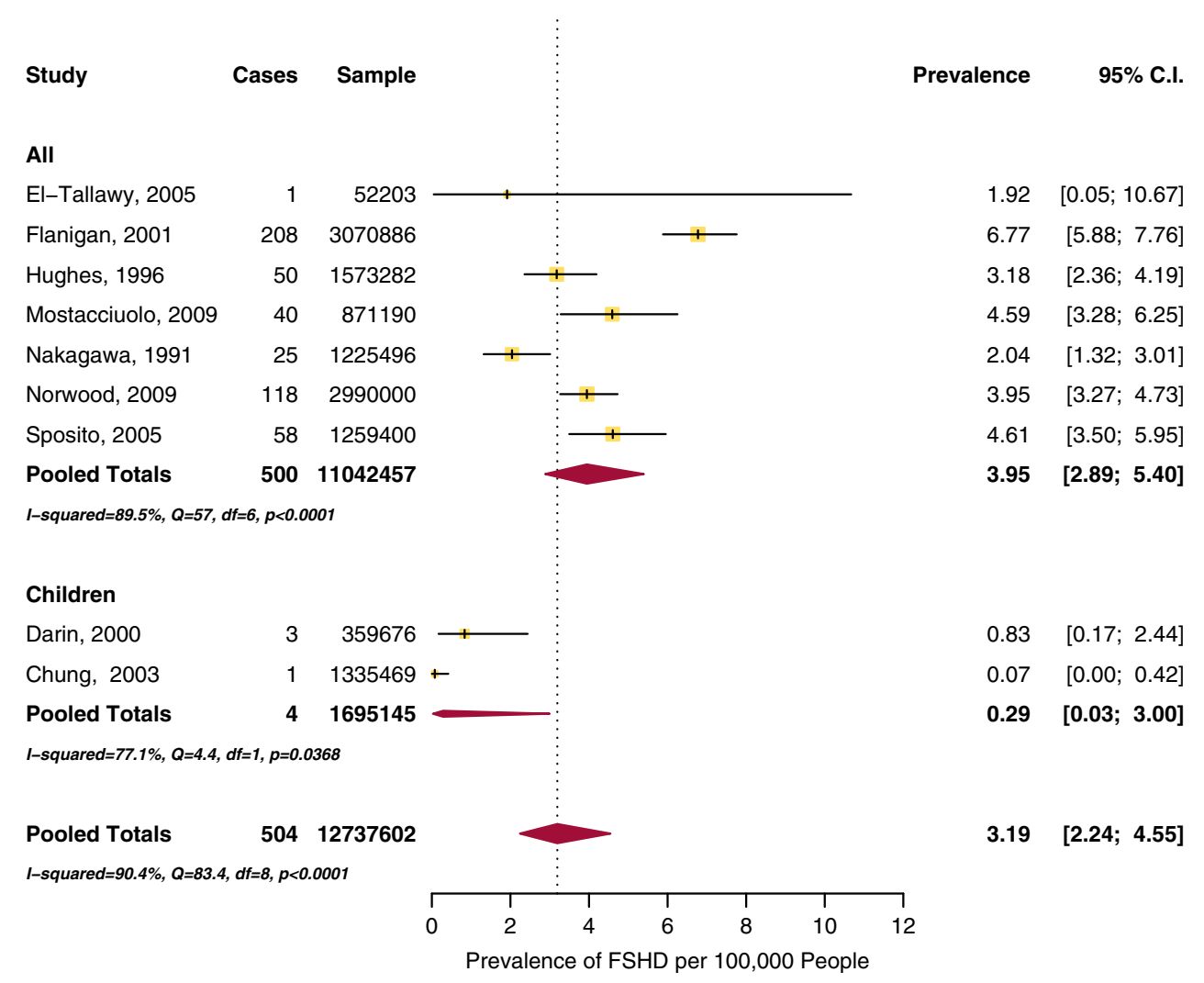

Figure 3: Forest plots of individual studies and pooled prevalence estimates of facioscapulohumeral muscular dystrophy (FSHD).

representative of the target population. All studies used standardized data collection methods and most used validated criteria to assess for the presence of muscular dystrophies. Only five studies reported estimates with their accompanying confidence intervals or by subgroups.

\section{DISCUSSION}

According to Emery's report in 1991, the prevalence of inherited neuromuscular disorders including Duchenne and Becker muscular dystrophies, spinal muscular atrophy, myotonic dystrophy, congenital myotonias, hereditary motor and sensory neuropathies, familial motor neuron disease, and familial myasthenia gravis was estimated to be around 28.6 per 100,000 , or 1 in $3500 .^{40}$ In the current systematic review, the overall worldwide prevalence of combined muscular dystrophies is estimated to be 16.14 per 100,000 , or 1 in 6200 . The reports of muscular dystrophies prevalence included in this systematic review were all population-based, used appropriate methodology, and were of good quality. However, several outlier estimates were observed. The overall prevalence estimates for facioscapulohumeral dystrophy in Egypt was high, likely as a result of the relatively small population sampled, the door-to-door survey methodology, and the number of cases identified. ${ }^{33}$ Also, the overall prevalence estimate for myotonic dystrophy type 1 in Spain of 26.53 per 100,000 is higher than in the other included studies without any clear methodological differences, possibly related to a founder effect. ${ }^{17}$ In contrast, a lower prevalence estimate of myotonic dystrophy was observed in China and Taiwan ( 0.37 and 0.46 per 100,000 , respectively); this may be attributed to variation in the availability of genetic testing for confirmation of diagnosis and restriction of the sample population to those younger than 19 years of age. ${ }^{35,36}$ Similarly, lower prevalence estimates were found in other systematic reviews of neurological conditions such as Huntington or Parkinson diseases in Asia. ${ }^{41,42}$ However, Darin and Tulinius also restricted their sample population to those younger than 16 years of age and demonstrated a more typical prevalence estimate of myotonic dystrophy at 5.0 per $100,000 .^{16}$ Therefore, the variation may also be related to genetic differences and/or the influence of migration on the prevalence of the inherited muscular dystrophies.

Comparison of pooled estimates demonstrates that myotonic dystrophy type 1 is the most prevalent muscular dystrophy in childhood and in the overall population, with a pooled prevalence of 8.26 (95\% CI, 7.99-13.68) per 100,000. Emery estimated an overall prevalence of 5.0 per 100,000 in adults. ${ }^{40}$ Much higher prevalence of myotonic dystrophy type 1 had been reported because of founder effect and geographical isolation. A prevalence of 158 per 100,000 was recently reported by Mathieu et al in 2012 at the Saguenay-Lac-Saint-Jean region in Northern Quebec, Canada; the prevalence has progressively declined over the past two decades because of reduced fertility rate. ${ }^{43}$ Facioscapulohumeral dystrophy is the second most prevalent muscular dystrophy; the pooled prevalence in all age groups from this study was 3.95 (95\% CI, 2.89-5.40) per 100,000, which is about twice as high as the estimate of 2 per 100,000 by Emery in $2001 .^{40}$ 


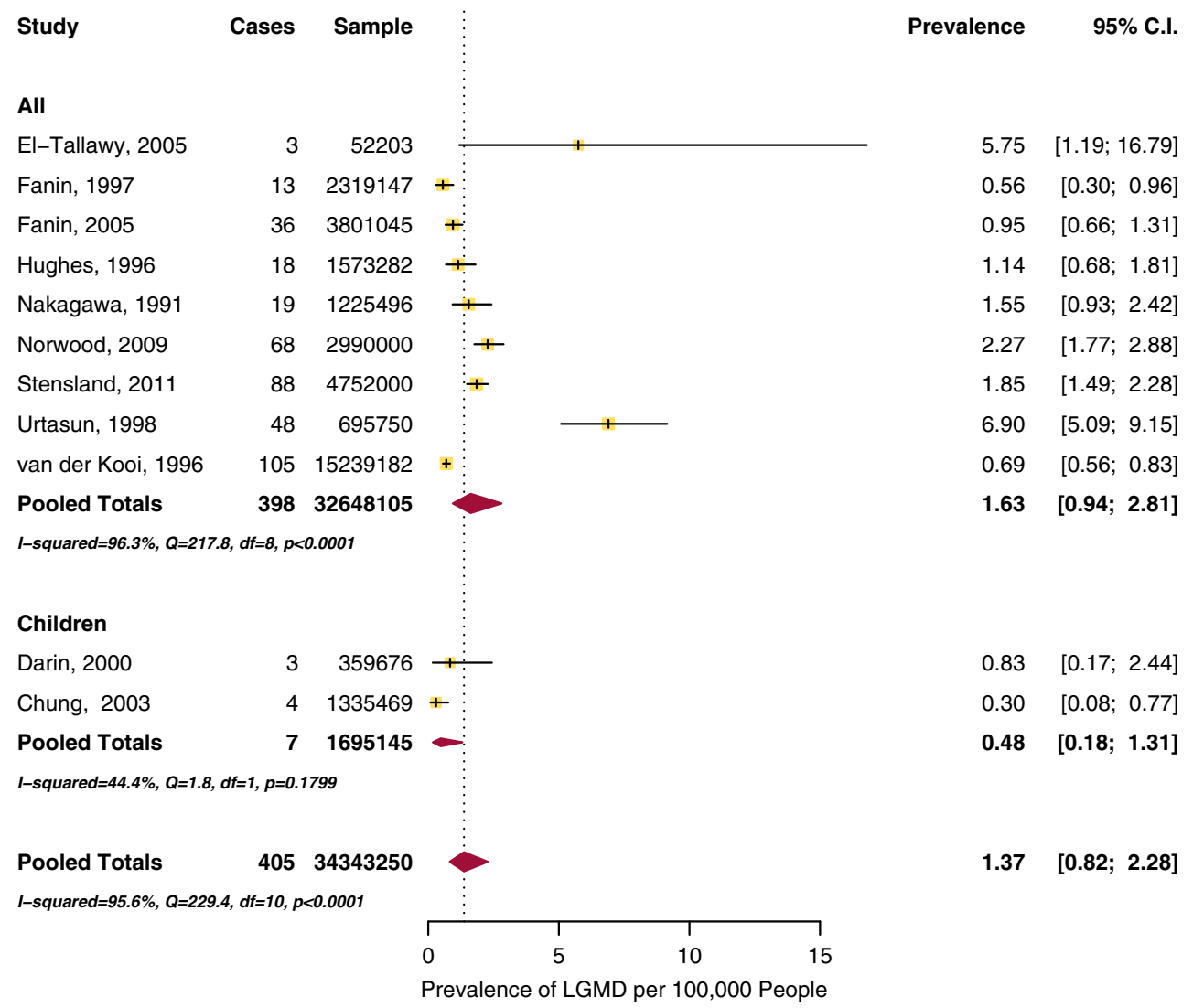

Figure 4: Forest plots of individual studies and pooled prevalence estimates of limb girdle muscular dystrophy (LGMD).

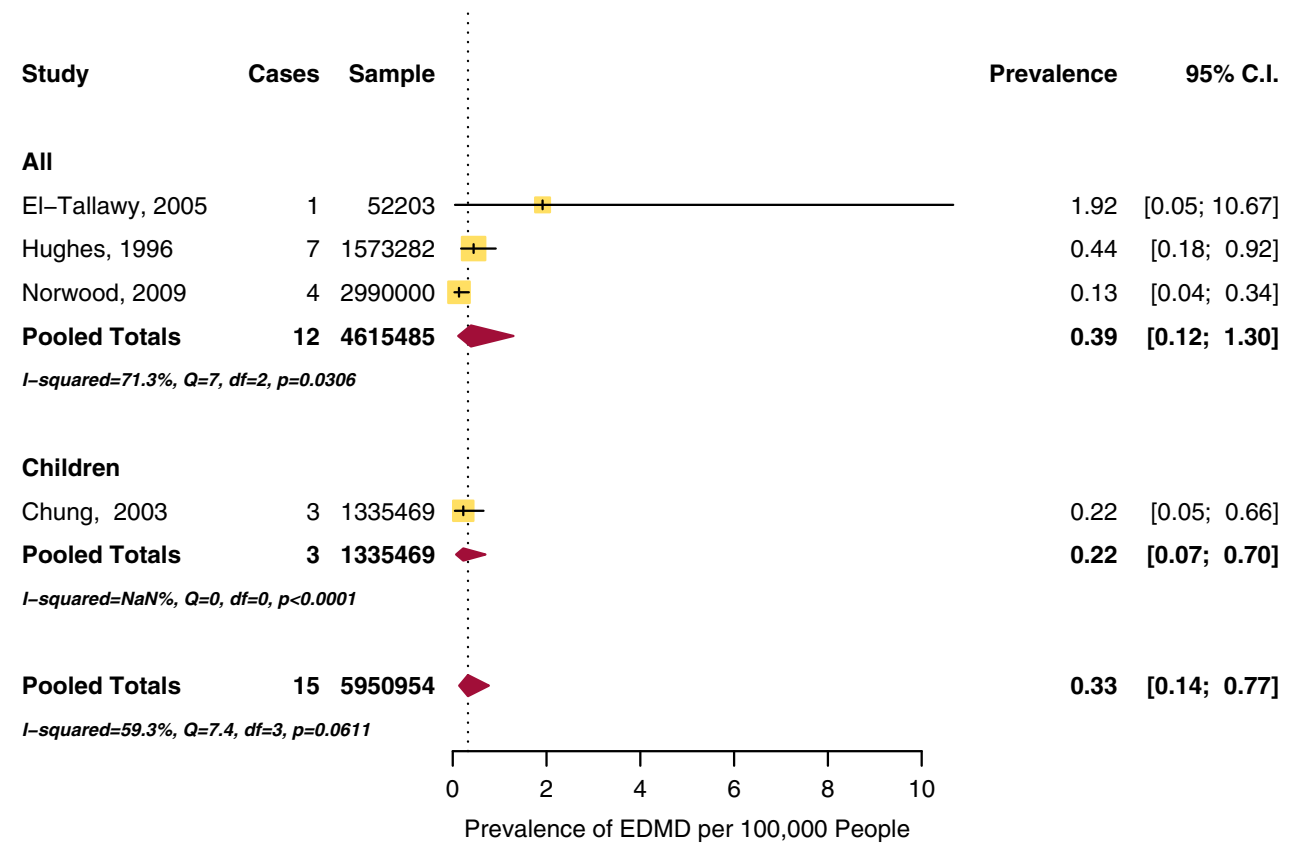

Figure 5: Forest plots of individual studies and pooled prevalence estimates of Emery-Dreifuss muscular dystrophy (EDMD). 


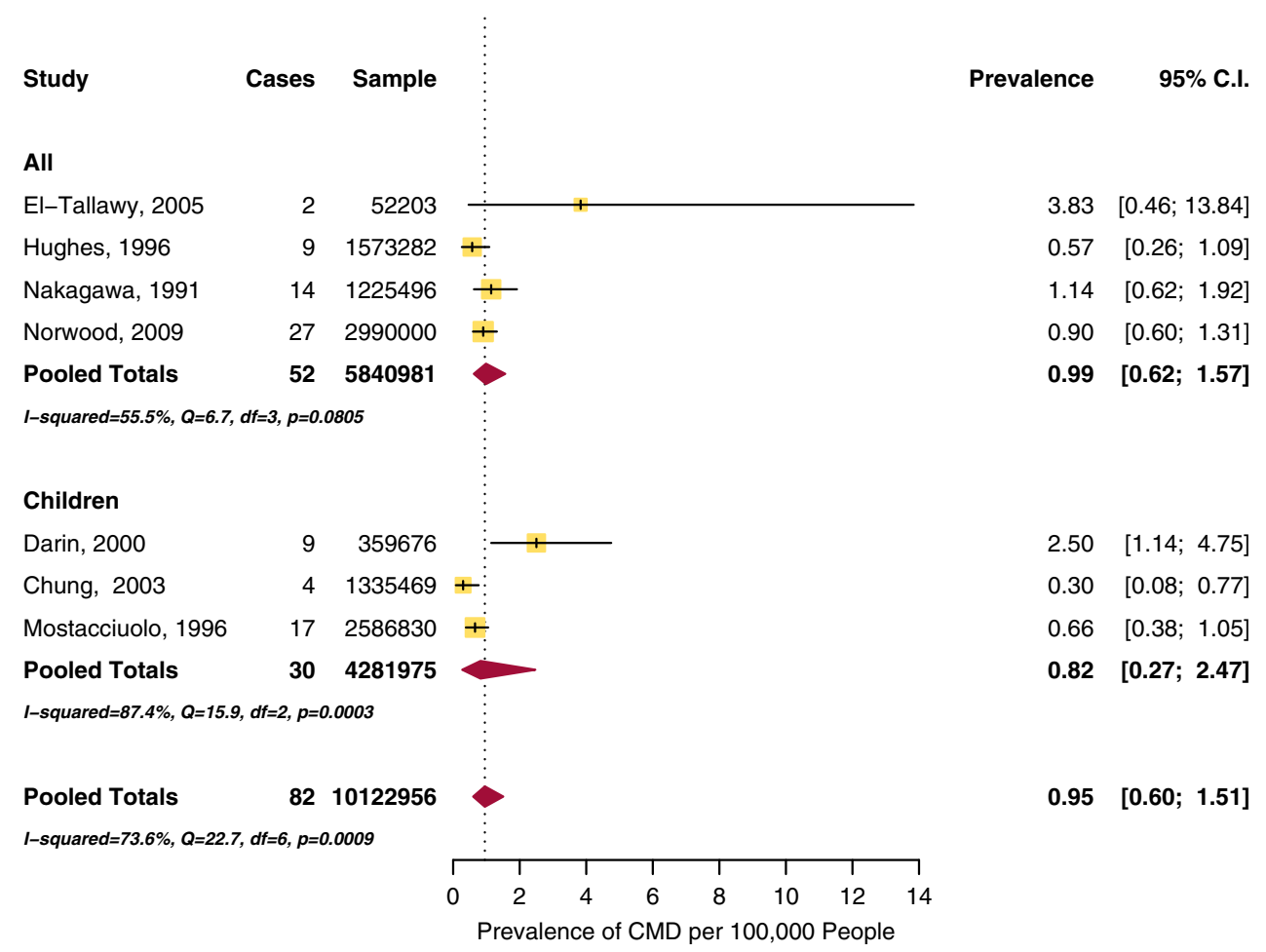

Figure 6: Forest plots of individual studies and pooled prevalence estimates of congenital muscular dystrophy (CMD).

Duchenne muscular dystrophy remains the most prevalent muscular dystrophy of childhood in boys. The estimated prevalence of Duchenne and Becker muscular dystrophies according to Emery was 6.3 and 2.4 per 100,000 , respectively, which is similar to our recent estimates of 4.78 (95\% CI, 1.94-11.81) and 1.53 (95\% CI: $0.26-8.94)$ per $100,000 .^{2}$

Variation in the reported prevalence of muscular dystrophies could be related to genetic variations between populations or ethnic groups as well as differences in available molecular diagnostic tools for accurate diagnosis. ${ }^{35,36}$ Furthermore, neuromuscular disorders are relatively uncommon in the general population, and one must often resort to hospital charts and other sources of medical information in the community for the number of diagnosed cases. The availability of such information varies among countries and within regions. As well, some affected individuals may not seek medical attention; undiagnosed cases therefore may lead to an underestimation of the true prevalence of muscular dystrophies. On the other hand, advances in research activity may generate an increased awareness in a region for a particular group of disorders, as may be seen by Norwood et al within the United Kingdom. ${ }^{26}$ Comparatively fewer cases of muscular dystrophy were diagnosed during the first 4 years of life, as indicated in a recent study on congenital myotonic dystrophy ${ }^{44}$; diagnostic difficulties may contribute to the lower prevalence of

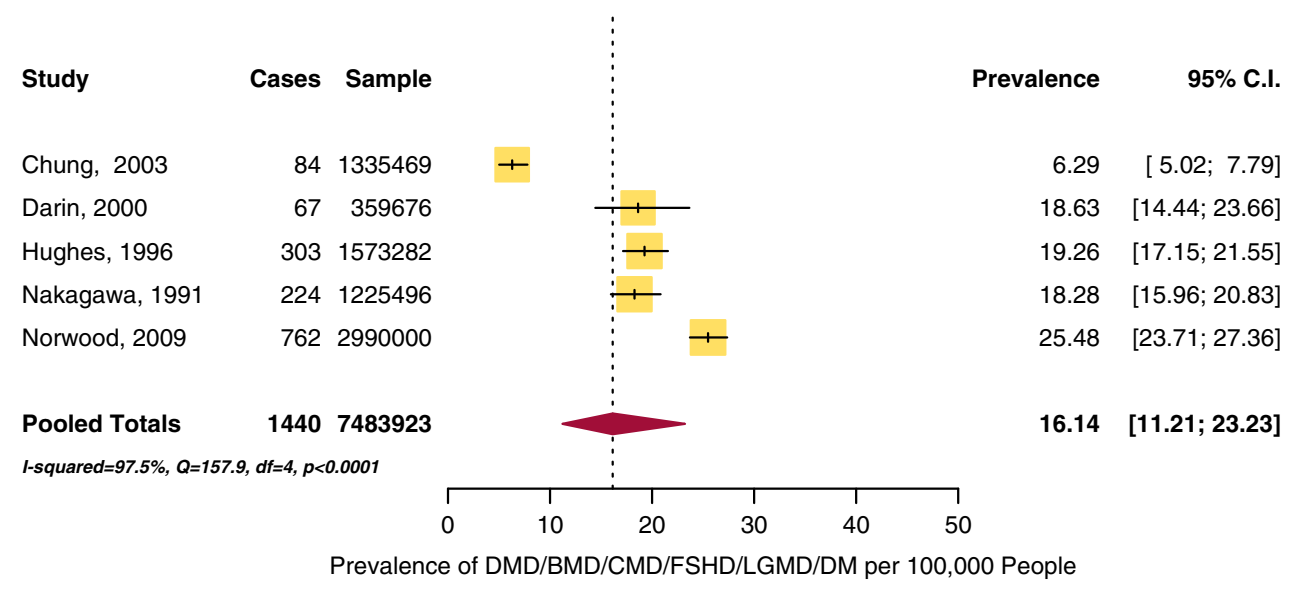

Figure 7: Forest plots of individual studies and pooled prevalence estimates of the combined muscular dystrophies $(M D s)$. 
Table 7: Quality scores of studies included in the muscular dystrophies systemic review

\begin{tabular}{|c|c|c|c|c|c|c|c|c|c|}
\hline Study, date & $\begin{array}{l}\text { Is the target } \\
\text { population } \\
\text { clearly } \\
\text { defined? }\end{array}$ & $\begin{array}{l}\text { Was either of } \\
\text { the following } \\
\text { ascertain- } \\
\text { ment method } \\
\text { used? }\end{array}$ & $\begin{array}{l}\text { Is the } \\
\text { response rate } \\
\geq 70 \% ?\end{array}$ & $\begin{array}{l}\text { Are } \\
\text { nonrespon- } \\
\text { ders clearly } \\
\text { described? }\end{array}$ & $\begin{array}{l}\text { Is the sample } \\
\text { representative of } \\
\text { the target } \\
\text { population? }\end{array}$ & $\begin{array}{l}\text { Were data } \\
\text { collection } \\
\text { methods } \\
\text { standar- } \\
\text { dized? }\end{array}$ & $\begin{array}{l}\text { Were validated } \\
\text { criteria used to } \\
\text { assess for the } \\
\text { presence/absence } \\
\text { of the disease? }\end{array}$ & $\begin{array}{l}\text { Are the estimates of } \\
\text { prevalence and incidence } \\
\text { given with confidence } \\
\text { intervals and in detail by } \\
\text { subgroup (if applicable)? }\end{array}$ & Total quality score \\
\hline Ballo, 1994 & Yes & No & Not reported & No & Yes & Yes & Yes & No & 4 \\
\hline Blumen, 1997 & Yes & Yes & Yes & Yes & Yes & Yes & Yes & No & 7 \\
\hline Bushby, 1991 & Yes & Yes & Yes & Yes & Yes & Yes & Yes & No & 7 \\
\hline Chung, 2003 & Yes & No & Yes & Yes & Unclear & Yes & Yes & No & 5 \\
\hline Darin, 2000 & Yes & Yes & Yes & Yes & Yes & Yes & Yes & Yes & 8 \\
\hline $\begin{array}{l}\text { De Munain, } \\
1993\end{array}$ & Yes & Yes & Yes & Yes & Yes & Yes & Yes & No & 7 \\
\hline $\begin{array}{l}\text { El-Tallawy, } \\
2005\end{array}$ & Yes & Yes & Not reported & Not reported & Yes & Yes & Yes & No & 5 \\
\hline Fanin, 1997 & Yes & No & Yes & Yes & Yes & Yes & Yes & No & 6 \\
\hline Fanin, 2005 & Yes & Yes & Yes & Yes & No & Yes & Yes & No & 7 \\
\hline Flanigan, 2001 & Yes & No & Not reported & Not reported & Yes & Yes & No & No & 3 \\
\hline Ford, 2006 & Yes & Yes & Yes & Yes & Yes & Yes & Yes & No & 7 \\
\hline $\begin{array}{c}\text { Greenberg, } \\
1988\end{array}$ & Yes & Yes & Yes & Yes & Yes & Yes & Yes & No & 7 \\
\hline Hsiao, 2003 & Yes & Yes & Yes & Yes & Yes & Yes & Yes & No & 7 \\
\hline Hughes, 1996 & Yes & Yes & Yes & Yes & Yes & Yes & Yes & No & 7 \\
\hline Jeppesen, 2003 & Yes & Yes & Yes & Yes & Yes & Yes & Yes & Yes & 8 \\
\hline Magee, 1999 & Yes & Yes & Yes & Yes & Yes & Yes & Yes & No & 7 \\
\hline Medica, 1997 & Yes & Yes & Yes & Yes & Yes & Yes & Yes & No & 7 \\
\hline $\begin{array}{l}\text { Mladenovic, } \\
2006\end{array}$ & Yes & Yes & Yes & Yes & Yes & Yes & Yes & Yes & 8 \\
\hline MMWR, 2009 & Yes & Yes & Yes & Yes & Yes & Yes & Yes & No & 7 \\
\hline $\begin{array}{l}\text { Mostacciuolo, } \\
1996\end{array}$ & Yes & Yes & Yes & Yes & Yes & Yes & Yes & No & 7 \\
\hline $\begin{array}{l}\text { Mostacciuolo, } \\
2009\end{array}$ & Yes & Yes & Yes & Yes & Yes & Yes & Yes & No & 7 \\
\hline $\begin{array}{l}\text { Nakagawa, } \\
1991\end{array}$ & Yes & Yes & Unclear & Unclear & Yes & Yes & Yes & No & 5 \\
\hline Norwood, 2009 & Yes & Yes & Yes & Yes & Yes & Yes & Yes & Yes & 8 \\
\hline Segel, 2003 & Yes & Yes & Yes & Yes & Yes & Yes & Yes & Yes & 8 \\
\hline Siciliano, 1999 & Yes & Yes & Yes & Yes & Yes & Yes & Yes & No & 7 \\
\hline Siciliano, 2001 & Yes & Yes & Yes & Yes & Yes & Yes & Yes & No & 7 \\
\hline Sposito, 2005 & Yes & Yes & Yes & Yes & Yes & Yes & Yes & No & 7 \\
\hline Stensland, 2011 & Yes & No & Yes & Yes & No & Yes & Yes & No & 5 \\
\hline Talkop, 2003 & Yes & Yes & Yes & Yes & Yes & Yes & Yes & Yes & 8 \\
\hline Urtasun, 1998 & Yes & Yes & Yes & Yes & Yes & Yes & Yes & No & 7 \\
\hline $\begin{array}{l}\text { Van der Kooi, } \\
1996\end{array}$ & Yes & yes & Yes & Yes & Yes & Yes & Yes & No & 7 \\
\hline
\end{tabular}


muscular dystrophies as reported in early childhood. Prevalence figures in school-aged children are therefore likely to give a better estimate of the true childhood prevalence of neuromuscular disorders. ${ }^{16}$

As previously mentioned, ${ }^{2}$ limitations of this systematic review include variability in methodology, nonrandom geographic distribution, and the lack of validated international classification of disease codes for the muscular dystrophies among the studies. ${ }^{45}$ The lack of genetic testing in earlier studies may also lead to an imprecise estimation of the true prevalence of the muscular dystrophies. It was not possible to calculate a pooled estimate of myotonic dystrophy type 2 as several of the epidemiologic studies were conducted prior to the discovery of the gene for type 2 disease. $^{4}$ There was evidence of publication bias, but only for facioscapulohumeral dystrophy. Flanigan et al reported a high prevalence of disease in a geographically and genetically restricted population ${ }^{39}$; there may be other studies with a lower prevalence of facioscapulohumeral dystrophy that were not identified in our search. Despite great efforts to ensure the search strategy to be as comprehensive as possible, we did not include abstracts, gray literature, or articles written in languages apart from English or French. Application of these results must be made in light of these limitations. Multiple sources of case ascertainment beyond clinical-based settings such as national registries, genetic databases, and patient organizations should be considered for future incidence or prevalence studies of the muscular dystrophies.

\section{CONCLUSION}

This is a meta-analysis of the minimum prevalence estimates for myotonic dystrophy, facioscapulohumeral dystrophy, limb girdle muscular dystrophies, congenital muscular dystrophies, and combined muscular dystrophies derived from studies around the world. Population-based registries for the muscular dystrophies were limited to parts of Europe, Asia, and North America only. Substantial gaps exist with no available data from many other continents, limiting the generalization of the reports. In the United States, the reported national costs of illness for Duchenne muscular dystrophy, myotonic dystrophy, and other progressive neuromuscular diseases has been estimated to exceed more than $\$ 1$ billion per year. ${ }^{46}$ Our pooled estimates are useful for calculating projections of expected case numbers in regions without accurate prevalence data facilitating estimation of health care burden, economic impact, and clinical resource requirements. Clinical research must continue to be anchored to epidemiological understanding to enable interpretation of relevance to, and effect of, the overall patient population.

\section{ACKNOWLEDGMENTS}

This study is part of the National Population Health Study of Neurological Conditions. We wish to acknowledge the membership of Neurological Health Charities Canada and the Public Health Agency of Canada for their contribution to the success of this initiative. Funding for the study was provided by the Public Health Agency of Canada. The opinions expressed in this publication are those of the authors/researchers, and do not necessarily reflect the official views of the Public Health Agency of Canada. We would like to acknowledge Diane Lorenzetti for her assistance in developing the search strategies. Nathalie Jetté holds a Population Health salary award from Alberta Innovates Health Solutions and a Canada Research Chair Tier 2 in Neurological Health Services Research.

\section{Disclosures}

TP has served as a consultant for and received consulting fees from Teva Canada; received an unrestricted grant from Shire Canda; and been a meeting attendee and received support to attend meetings for Allergan Canada. NJ has received a research grant and research support paid to the university from the Public Health Agency of Canada; been an award recipient and received a salary award paid to the university from the Canada Research Chair Program; and received a salary award paid to the university from Albert Innovates Health Solutions. JM, KF, JD, LD, and LK have nothing to disclose.

\section{REFERENCES}

1. Narayanaswami P, Weiss M, Selcen D, David W, Raynor E, Carter $\mathrm{G}$, et al. Evidence-based guideline summary: Diagnosis and treatment of limb-girdle and distal dystrophies: Report of the guideline development subcommittee of the American academy of neurology and the practice issues review panel of the American association of neuromuscular \& electrodiagnostic medicine. Neurology. 2014;83:1453-63.

2. Mah JK, Korngut L, Dykeman J, Day L, Pringsheim T, Jette N. A systematic review and meta-analysis on the epidemiology of Duchenne and Becker muscular dystrophy. Neuromuscul Disord. 2014;24:482-91.

3. Brook JD, McCurrach ME, Harley HG, Buckler AJ, Church D, Aburatani $\mathrm{H}$, et al. Molecular basis of myotonic dystrophy: expansion of a trinucleotide (CTG) repeat at the 3 , end of a transcript encoding a protein kinase family member. Cell. 1992;68:799-808.

4. Ranum LP, Rasmussen PF, Benzow KA, Koob MD, Day JW. Genetic mapping of a second myotonic dystrophy locus. Nat Genet.. 1998;19:196-8.

5. Campbell C, Sherlock R, Jacob P, Blayney M. Congenital myotonic dystrophy: assisted ventilation duration and outcome. Pediatrics. 2004;113:811-6.

6. Padberg GW, Lunt PW, Koch M, Fardeau M. Diagnostic criteria for facioscapulohumeral muscular dystrophy. Neuromuscul Disord. 1991;1:231-4.

7. Lemmers RJ, Tawil R, Petek LM, Balog J, Block GJ, Santen GW, et al. Digenic inheritance of an SMCHD1 mutation and an fshd-permissive D4Z4 allele causes facioscapulohumeral muscular dystrophy type 2. Nat Genet. 2012;44:1370-4.

8. Jardine PE, Koch MC, Lunt PW, Maynard J, Bathke KD, Harper PS, et al. De novo facioscapulohumeral muscular dystrophy defined by DNA probe p13e-11 (D4F104S1). Arch Dis Child. 1994;71:221-7.

9. Mercuri E, Muntoni F. Muscular dystrophies. Lancet. 2013;381:845-60.

10. Bönnemann CG, Wang CH, Quijano-Roy S, Deconinck N, Bertini E, Ferreiro A, et al. Diagnostic approach to the congenital muscular dystrophies. Neuromuscul Disord. 2014;24:289-311.

11. Caesar-Chavannes C, MacDonald S. Cross-Canada Forum - National Population Health Study of Neurological Conditions in Canada. Chronic Dis Inj Canada. 2013;33:188-91.

12. Boyle M. Guidelines for evaluating prevalence studies. Evid Based Mental Health. 1998;1:37-9.

13. R: A language and environment for statistical computing [computer program]. Vienna, Austria; 2011.

14. meta: Meta-Analysis with $\mathrm{R}$ [computer program]. Version 1.6-1; 2010.

15. Viechtbauer W. Conducting meta-analyses in $\mathrm{R}$ with the metafor package. J Stat Softw. 2010;36:1-48.

16. Darin N, Tulinius M. Neuromuscular disorders in childhood: a descriptive epidemiological study from western Sweden. Neuromuscul Disord. 2000;10:1-9. 
17. López de Munain A, Blanco A, Emparanza JI, Poza JJ, Martí Massó JF, Cobo A, et al. Prevalence of myotonic dystrophy in Guipúzcoa (Basque country, Spain). Neurology. 1993;43:1573-6.

18. Fanin M, Duggan DJ, Mostacciuolo ML, Martinello F, Freda MP, Sorarù G, et al. Genetic epidemiology of muscular dystrophies resulting from sarcoglycan gene mutations. J Med Genet. 1997;34:973-7.

19. Fanin M, Nascimbeni AC, Fulizio L, Angelini C. The frequency of limb girdle muscular dystrophy $2 \mathrm{~A}$ in northeastern Italy. Neuromuscul Disord. 2005;15:218-24.

20. Hughes MI, Hicks EM, Nevin NC, Patterson VH. The prevalence of inherited neuromuscular disease in Northern Ireland. Neuromuscul Disord. 1996;6:69-73.

21. Magee A, Nevin NC. The epidemiology of myotonic dystrophy in northern Ireland. Community Genet. 1999;2:179-83.

22. Medica I, Marković D, Peterlin B. Genetic epidemiology of myotonic dystrophy in Istria, Croatia. Acta Neurol Scand. 1997;95:164-6

23. Mladenovic J, Pekmezovic T, Todorovic S, Rakocevic-Stojanovic V, Savic D, Romac S, et al. Survival and mortality of myotonic dystrophy type 1 (Steinert's disease) in the population of Belgrade. Eur J Neurol. 2006;13:451-4.

24. Mostacciuolo ML, Miorin M, Martinello F, Angelini C, Perini P, Trevisan CP. Genetic epidemiology of congenital muscular dystrophy in a sample from north-east Italy. Hum Genet. 1996;97:277-9.

25. Mostacciuolo ML, Pastorello E, Vazza G, Miorin M, Angelini C, Tomelleri G, et al. Facioscapulohumeral muscular dystrophy: Epidemiological and molecular study in a north-east Italian population sample. Clin Genet. 2009;75:550-5.

26. Norwood FL, Harling C, Chinnery PF, Eagle M, Bushby K, Straub V. Prevalence of genetic muscle disease in northern England: in-depth analysis of a muscle clinic population. Brain. 2009;132:3175-86

27. Siciliano G, Manca M, Gennarelli M, Angelini C, Rocchi A, Ludice A, et al. Epidemiology of myotonic dystrophy in Italy: Re-appraisal after genetic diagnosis. Clin Genet. 2001;59:344-9.

28. Sposìto R, Pasquali L, Galluzzi F, Rocchi A, Solito B, Soragna D, et al. Facioscapulohumeral muscular dystrophy type $1 \mathrm{~A}$ in northwestern Tuscany: a molecular genetics-based epidemiological and genotype-phenotype study. Genet Test. 2005;9:30-6.

29. Stensland E, Lindal S, Jonsrud C, Torbergsen T, Bindoff LA, Rasmussen M, et al. Prevalence, mutation spectrum and phenotypic variability in Norwegian patients with limb girdle muscular dystrophy 2I. Neuromuscul Disord. 2011;21:41-6.

30. Urtasun M, Sáenz A, Roudaut C, Poza JJ, Urtizberea JA, Cobo AM, et al. Limb-girdle muscular dystrophy in Guipúzcoa (Basque country, Spain). Brain. 1998;121:1735-47.

31. van der Kooi AJ, Barth PG, Busch HF, de Haan R, Ginjaar HB, van Essen AJ, et al. The clinical spectrum of limb girdle muscular dystrophy. A survey in the Netherlands. Brain. 1996;119: 1471-80.

32. Blumen SC, Nisipeanu P, Sadeh M, Asherov A, Blumen N, Wirguin Y, et al. Epidemiology and inheritance of oculopharyngeal muscular dystrophy in Israel. Neuromuscul Disord. 1997;7:S38-40.

33. El-Tallawy HN, Khedr EM, Qayed MH, Helliwell TR, Kamel NF. Epidemiological study of muscular disorders in Assiut, Egypt. Neuroepidemiology. 2005;25:205-11.

34. Segel R, Silverstein S, Lerer I, Kahana E, Meir R, Sagi M, et al. Prevalence of myotonic dystrophy in Israeli Jewish communities: inter-community variation and founder premutations. Am J Med Genet A. 2003;119A:273-8.

35. Chung B, Wong V, Ip P. Prevalence of neuromuscular diseases in Chinese children: A study in southern China. J Child Neurol. 2003;18:217-9.

36. Hsiao KM, Chen SS, Li SY, Chiang SY, Lin HM, Pan H, et al. Epidemiological and genetic studies of myotonic dystrophy type 1 in Taiwan. Neuroepidemiology. 2003;22:283-9.

37. Nakagawa M, Nakahara K, Yoshidome H, Suehara M, Higuchi I, Fujiyama J, et al. Epidemiology of progressive muscular dystrophy in Okinawa, Japan. Classification with molecular biological techniques. Neuroepidemiology. 1991;10:185-91.

38. Ford C, Kidd A, Hammond-Tooke G. Myotonic dystrophy in Otago, New Zealand. N Z Med J. 2006;119:1573-6.

39. Flanigan KM, Coffeen CM, Sexton L, Stauffer D, Brunner S, Leppert MF. Genetic characterization of a large, historically significant Utah kindred with facioscapulohumeral dystrophy. Neuromuscul Disord. 2001;11:525-9.

40. Emery A. Population frequencies of inherited neuromuscular diseases - a world survey. Neuromuscul Disord. 1991;1:19-29.

41. Pringsheim T, Wiltshire K, Day L, Dykeman J, Steeves T, Jette N. The incidence and prevalence of Huntington's disease: a systematic review and meta-analysis. Mov Disord. 2012;27:1083-91.

42. Pringsheim T, Jette N, Frolkis A, Steeves TD. The prevalence of Parkinson's disease: a systematic review and meta-analysis. Mov Disord. 2014;29:1583-90.

43. Mathieu J, Prévost C. Epidemiological surveillance of myotonic dystrophy type 1: a 25 -year population-based study. Neuromuscul Disord. 2012;22:974-9.

44. Campbell C, Levin S, Siu VM, Venance S, Jacob P. Congenital myotonic dystrophy: Canadian population-based surveillance study. J Pediatr. 2013;163:120-5.

45. St. Germaine-Smith C, Metcalfe A, Pringsheim T, Roberts JL, Beck CA, Hemmelgarn BR, et al. What are the best diagnostic codes to identify neurological conditions in population-based administrative health data? An international systematic review of validation studies. Neurology. 2012;79:1049-55.

46. Larkindale J, Yang W, Hogan PF, Simon CJ, Zhang Y, Jain A, et al. Cost of illness for neuromuscular diseases in the United States. Muscle Nerve. 2014;49:431-8. 